\title{
A search for scanning residue in recognition memory
}

\author{
PAUL MUTER and BENNET B. MURDOCK, JR. \\ University of Toronto, Toronto, Ontario MSS 1A1, Canada
}

\begin{abstract}
An attempt was made to find evidence for scanning residue in a modified Sternberg (1966) procedure. Lists of two, three, or four words drawn from a large pool were presented to four subjects in a completely within-subjects design. Trials were in pairs such that the list was the same for both trials within a pair. The test item on Trial 1 was either a word, which cued the subject to perform a recognition memory task, or a digit, which cued the subject to perform an irrelevant task. The test item on Trial 2 was always a word. No scanning residue was found: 'The slope of the reaction time/set size function on Trial 2 was not affected by the type of test on Trial 1.
\end{abstract}

Several models of recognition memory have postulated a scan of the memorized items. To varying extents, these models are consistent with data. However, direct evidence of scanning-for example, evidence of aftereffects of scanning, or scanning residue-has not been provided. An earlier experiment yielded no scanning residue in recognition memory for items from long lists (Murdock, Hockley, \& Muter, in press, Experiment 3). The purpose of the present study was to look for scanning residue in the recognition of items from short lists.

The scanning models under consideration were proposed to explain the results of an experiment by Sternberg (1966), who asked subjects to indicate whether a test item was a member of a previously memorized set of one to six items. Mean reaction time was a linear function of set size, and the slope of the function for positive items (test items which were members of the list) was equal to the slope for negative items (test items which were not members of the list). Several theorists have proposed that, in this task, a representation of the test item is compared to representations in memory of the memorized set and a match is sought. This scan may be serial and exhaustive (Sternberg, 1966), serial and self-terminating (Theios, Smith, Haviland, Traupmann, \& Moy, 1973), or parallel (Murdock, 1971). The major alternative to scanning is direct access and trace strength assessment (e.g., Baddely \& Ecob, 1973; Corballis, Kirby, \& Miller, 1972).

According to a direct access view, when a test item is presented, the traces of the nontarget items in the memory set should not be affected in any specific way. (They are subject to the general "interfering" effect of any event upon a trace; e.g., Norman \& Waugh, 1968.)

This research was supported by Research Grants APA146 from the National Research Council of Canada and OMHF164 from the Ontario Mental Health Foundation to the second author. The authors wish to thank Howard Kaplan for designing the operating system which made the programming of the experiment possible.
The same statement cannot be made with respect to the scanning models: The scanning of representations of nontarget items may change these representations in some way. For example, the scanning of representations of nontarget items may facilitate subsequent scanning of these representations.

There is some evidence that the slope of the set size function (i.e., the function relating mean reaction time and set size) decreases over trials (Kristofferson, 1972; Ross, 1970). However, the decrease in slope may have been produced not by repeated scanning, but by repeated presentations (including tests) of items in the memory set. The present study avoided this confounding by manipulating the amount of prior scanning of the memory set (assuming scanning occurs) without varying the number of prior presentations of relevant items.

A modification of the Sternberg (1966) varied-set procedure was used. Trials were in pairs such that the memory set was identical for both trials within the pair. For half the pairs, on Trial 1 a cue to perform an irrelevant task was presented instead of a normal test; therefore, presumably no scanning occurred. If scanning occurs in the Sternberg paradigm, and if scanning facilitates subsequent scanning, Trial 2 scanning should be faster (the slope of the set size function should be shallower) when the normal task is performed on Trial 1 than when the irrelevant task is performed on Trial 1. If direct access occurs (and if data from trial pairs where the same positive item is tested on each trial are ignored), the slope on Trial 2 should not be affected by the presence or absence of a normal test on Trial 1.

\section{METHOD}

Subjects

One undergraduate and three graduate students at the University of Toronto served as subjects. The three females and one male ranged from 21 to 23 years of age, and were paid $\$ 30$ each for their participation. 
Apparatus and Stimuli

Randomization and presentation of all stimuli were controlled by a PDP-12A computer. Subjects sat in front of a cathode-ray screen and on each trial responded by pressing one of two keys resting under their index fingers.

The stimulus words were drawn from a pool of 1,080 common English two-syllable words not more than eight letters long, with homophones, contractions, archaic words, and proper nouns excluded.

\section{Procedure}

A trial pair consisted of the following sequence. After the subject pressed a key to indicate that he was ready, the memory set of two, three, or four words was presented at the rate of $1.2 \mathrm{sec} /$ word ( $1 \mathrm{sec}$ of presentation followed by a blank screen for $.2 \mathrm{sec}$ ). After a 2 -sec pause and a $1 / 2$-sec warning signal ("***”), a test item was displayed and remained on the screen until the subject pressed a key. There was a $1-\mathrm{sec}$ pause before the memory set was re-presented, in the same order, and the Trial 2 test was given. A message appeared on the screen indicating whether the subject had performed correctly on the two trials.

The memory set for each trial pair consisted of words which had not been presented before in that session. Negative test words were words which had not been presented before in that session, but subjects were not informed of this constraint. Rather, they were instructed simply to press the key under their right index finger if a test word was one of the two, three, or four words just presented, and to press the key under their left index finger if it was not. Subjects were asked to respond as quickly as possible, but to strive for very nearly $100 \%$ accuracy.

For half the trial pairs for each subject, a digit instead of a word was presented as the test on Trial 1 . Subjects pressed the left key if the digit was between 0 and 4 , and the right key if the digit was between 5 and 9 . Thus, there were eight types of trials: The test on Trial 1 could be a negative word, a positive word, a digit between 0 and 4 , or a digit between 5 and 9 ; for each of these four possibilities, the test on Trial 2 could be a negative word or a positive word. The serial position of positive test words was determined randomly. Within a block of trials, all 24 possible trial pairs (eight types times three set sizes) were presented in a random order. Each session consisted of six such blocks, and subjects were permitted to take rests between blocks. The four subjects completed 13 40-min sessions each, at the rate of approximately four sessions per week. Subjects were informed that the first session was for practice only, and data from practice sessions were not included in any analyses.

\section{RESULTS}

Trial 2 results to be presented do not include the small proportion of trial pairs on which the same positive item was tested on both trials. [If these deletions are not made, all significant effects to be reported remain significant $(p<.01)$, and all nonsignificant effects remain nonsignificant.] Similarly, Trial 2 results do not include the trial pairs for which an error occurred on Trial 1. The overall proportion of errors on Trial 1 was .012 for positive words, .004 for negative words, and .007 for digits.

Trial 2 error rates combined across sessions and subjects are presented in Table 1. The proportion of errors was very low, and incorrect responses were excluded from all reaction time data to be reported.

Mean reaction time as a function of set size for
Table 1

Proportion of Errors on Trial 2

\begin{tabular}{cccccc}
\hline & \multicolumn{2}{c}{ Positives } & & \multicolumn{2}{c}{ Negatives } \\
\cline { 2 - 3 } \cline { 5 - 6 } $\begin{array}{r}\text { Set } \\
\text { Size }\end{array}$ & $\begin{array}{c}\text { Word Test } \\
\text { on Trial 1 }\end{array}$ & $\begin{array}{c}\text { Digit Test } \\
\text { on Trial 1 }\end{array}$ & & $\begin{array}{l}\text { Word Test } \\
\text { on Trial 1 }\end{array}$ & $\begin{array}{c}\text { Digit Test } \\
\text { on Trial 1 }\end{array}$ \\
\hline 2 & .002 & .003 & & .007 & .003 \\
3 & .008 & .012 & & .005 & .005 \\
4 & .010 & .005 & & .002 & .002 \\
\hline
\end{tabular}

Trial 2 responses is plotted in Figure 1. The best-fitting straight lines (least squares to overall means) are drawn for the four types of trials of major interest. The presence of a prior word test had no effect on the slopes of the set size functions. The analysis of variance of Trial 2 reaction times revealed no interaction between type of test on Trial 1 (word or digit) and set size $[F(2, \infty)<1]$.

The presence of a word test on Trial 1, compared to an irrelevant digit test, produced faster reaction times for Trial 2 negative responses, but slower reaction times for Trial 2 positive responses. The interaction between type of Trial 1 test and type of Trial 2 test (negative or positive) was significant $[F(1, \infty)=44.46, p<.001]$. An analysis of variance of Trial 2 positives yielded a significant main effect of Trial 1 test type $[F(1, \infty)=28.03$, $\mathrm{p}<.001]$. The absolute magnitude of this effect was $14.5 \mathrm{msec}$. For Trial 2 negatives, the Trial 1 test type effect, $13.6 \mathrm{msec}$ in the opposite direction, was also significant $[F(1, \infty)=19.28, \mathrm{p}<.001]$.

\section{DISCUSSION}

The interaction between Trial 1 test type (word or digit) and Trial 2 test type (positive or negative) was totally unexpected. A possible interpretation of this interaction is that a word test on Trial 1 induces a more conservative criterion (a bias toward saying "no") on Trial 2. However, this interpretation would predict fewer Trial 2 false alarms and hits with a word test on Trial 1 than with a digit test on Trial 1 . Table 1 reveals that these predictions are not borne out.

There is clearly no evidence of scanning residue in the present

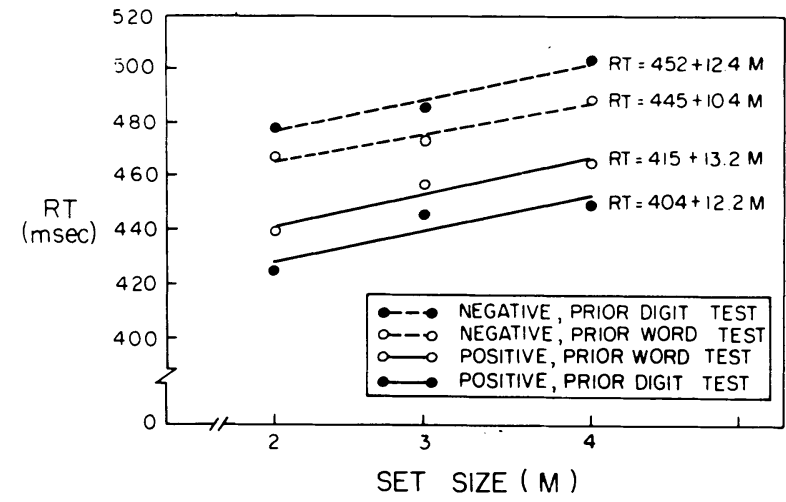

Figure 1. Mean Trial 2 reaction time as a function of set size, Trial 1 test type (word or digit), and Trial 2 test type (positive or negative). 
experiment. Trial 2 slopes were the same when a word test occurred on Trial 1 as when an irrelevant digit test occurred on Trial 1 . Of course, this finding by no means proves that scanning did not occur. Perhaps scanning occurred but scanning has no aftereffects. Perhaps scanning occurred and scanning leaves aftereffects, but the present experiment was not sufficiently sensitive to reveal them.

It is also possible that the present experiment yielded no scanning residue for one or more of the following reasons: The slopes were unusually shallow, the re-presentation of the memory set on Trial 2 may have eliminated any scanning residue, or there may have been something unusual about drawing the memory set from a large pool of items. To evaluate these possibilities, an extra subject was run. The method for this subject was identical with the following exceptions: She was not a graduate student (Hunt, Frost, \& Lunneborg, 1973, have demonstrated a relationship between verbal intelligence measures and slope in the Sternberg paradigm); the memory set was not re-presented for Trial 2; and the memory items were letters of the alphabet. For this subject, with a prior letter test the Trial 2 slope was $39.2 \mathrm{msec}$, and with a prior digit test the Trial 2 slope was 39.9 msec. (Standard errors of the slopes were less than $6 \mathrm{msec}$.) Again, no scanning residue was found.

Though experiments to date have had negative, and therefore inconclusive, results, we feel that the general technique of looking for scanning residue is a potentially valuable tool in determining whether high-speed scanning occurs in recognition memory.

\section{REFERENCES}

Baddeley, A. D., \& EcoB, J. R. Reaction time and short-term memory: Implications of repetition effects for the high-speed exhaustive scan hypothesis. Quarterly Journal of Experimental Psychology, 1975, 25, 229-240.

Corballis, M. C., Kirby, J., \& Miller, A. Access to elements of a memorized list. Journal of Experimental Psychology, 1972, 94, 185-190.

Hunt, E., Frost, N., \& Lunneborg, C. Individual differences in cognition: $A$ new approach to intelligence. In G. H. Bower (Ed.), The psychology of learning and motivation: Advances in research and theory (Vol. 7). New York: Academic Press, 1973. Pp. 87-122.

Kristufferson, M. W. When item recognition and visual search functions are similar. Perception \& Psychophysics, 1972, 12, 379-384.

Murdock, B. B., JR. A parallel-processing model for scanning. Perception \& Psychophysics, 1971, 10, 289-291.

Murdock, B. B., Jr., Hockley, W. E.. \& Mutek, P. Two tests of the conveyor-belt model for iten recognition. Canadiun Journal of Psychology, in press.

Norman, D. A., \& Waugh, N. C. Stimulus and response interference in recognition-memory experiments. Journal of Experimentul Psychology, 1968, 78, 551-559.

Ross, J. Extended practice with a single-character classification task. Perception \& Psychophysics, 1970, 8, 276-278.

Sternerg, S. High-speed scanning in human memory. Science. $1966,153,652-654$.

Theios, J., Smith, P. G., Haviland, S. E., Traupmann, J., d Moy, M. C. Memory scanning as a serial self-terminating process. Journal of Experimental Psychology, 1973, 97, 323-336.

(Received for publication March 4, 1977.) 